$\stackrel{N / N}{=}$

Global burnals Inc.

if

\title{
Knowledge, Attitude, Risk and Fear Assessment of Health Professionals Towards Covid-19 in Perspective of Workplace, Local and National Policy
}

By Ram Lochan Yadav, Laxmi Kumari Yadav, Rosan Churasiya \& Md. Nazrul Islam

Abstract-Background: Health professionals, the frontline fighters, are under high risk of being infected with a novel severe acute respiratory syndrome coronavirus 2 (SARS-CoV- 2). Many health workers in the world, including Nepal, have lost their lives in fighting with COVID-19. Thus, we assessed the knowledge, attitude, risk, and fear among health professionals towards COVID19 and evaluated their satisfaction with local and governmental policies of Nepal.

Methods: A self-administered questionnaire-based descriptive cross-sectional study included 150 (male-44\% and female-56\%) health professionals with mean age 26.14 \pm 6.092 years working at Chitwan Medical College, Nepal. The questionnaire included 40 statements having four categories to assess 1) the participant's knowledge about COVID-19, 2) the risk and attitude, 3) their fears, and 4) stake holder's role in encouraging health professionals to allay their fears and avert negative attitudes.

Keywords: COVID-19, health professionals, knowledge, risks, fear, encouragement.

\section{GJMR-F Classification: NLMC Code: W 84}

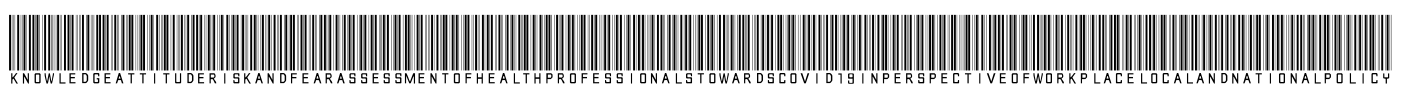

Strictly as per the compliance and regulations of:

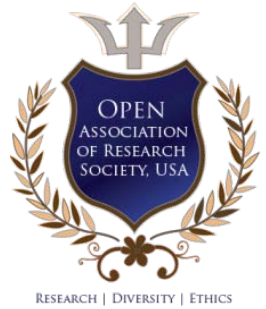

(c) 2020. Ram Lochan Yadav, Laxmi Kumari Yadav, Rosan Churasiya \& Md. Nazrul Islam. This is a research/review paper, distributed under the terms of the Creative Commons Attribution-Noncommercial 3.0 Unported License http://creativecommons.org/licenses/by-nc/3.0/), permitting all non-commercial use, distribution, and reproduction in any medium, provided the original work is properly cited. 


\title{
Knowledge, Attitude, Risk and Fear Assessment of Health Professionals Towards Covid-19 in Perspective of Workplace, Local and National Policy
}

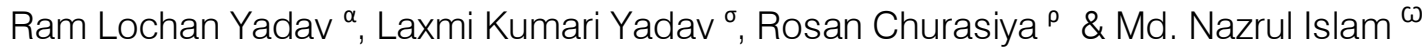

Abstract- Background: Health professionals, the frontline fighters, are under high risk of being infected with a novel severe acute respiratory syndrome coronavirus 2 (SARS-CoV2). Many health workers in the world, including Nepal, have lost their lives in fighting with COVID-19. Thus, we assessed the knowledge, attitude, risk, and fear among health professionals towards COVID-19 and evaluated their satisfaction with local and governmental policies of Nepal.

Methods: A self-administered questionnaire-based descriptive cross-sectional study included 150 (male-44\% and female$56 \%$ ) health professionals with mean age 26.14 26.092 years working at Chitwan Medical College, Nepal. The questionnaire included 40 statements having four categories to assess 1) the participant's knowledge about COVID-19, 2) the risk and attitude, 3) their fears, and 4) stake holder's role in encouraging health professionals to allay their fears and avert negative attitudes. The participants were asked to address their responses to each statement using a combination of YES-NO and Likert scale rating kept at the end of every statement. The descriptive statistics were applied to analyze the collected data using SPSS v.21.

Results: All the participants (100\%) mentioned COVID-19, a viral disease that started from China transmitted rapidly through aerosols. SARS COV-2 has an incubation period of up to 14 days $(117,78 \%)$, and diagnosis $(78.7 \%)$ requires a lab test. Over $56 \%$ rated that death is not imminent after infection. They agreed (98\%) with its flue like clinical presentations. The majority of them (88\%) were afraid of working in a hospital due to an unsafe working place $(65 \%)$. They $(92 \%)$ strongly pointed out the failure of the national and local policy to uplift the social security and to expand adequate testing centers $(92.7 \%)$. More than $65 \%$ indicated a lack of training and $70 \%$ were unaware of any stimulus package.

Conclusion: Health professionals bear adequate knowledge of COVID-19. However, the inadequate hospital work safety, poor infection control, lack of standard local and governmental strategies to empower financial, social, and health security to health care providers, most of them have lost their motivation to go to work in the hospital. The standard policies needed to

Author a: Department of Clinical Physiology, Chitwan Medical College, Bharatpur, Nepal. e-mail: dr.ramlochan04@gmail.com

Author o: Department of Microbiology, Chitwan Medical College, Bharatpur, Nepal.

Author p: Department of Pharmacy, Chitwan Medical College, Bharatpur, Nepal.

Author w: Department of Physiology, College of Pharmacy, University of Hafr Al Batin, Kingdom of Saudi Arabia. provide intensive training and boost them emotionally and socially for better crisis management and avert their negative attitudes.

Keywords: COVID-19, health professionals, knowledge, risks, fear, encouragement.

\section{INTRODUCTION}

- he coronavirus pandemic, also known as COVID19 Pandemic, is a viral disease rapidly spreading throughout the globe caused by a novel severe acute respiratory syndrome coronavirus 2 (SARS-CoV-2) previously named as 2019-n Cov1. The disease was first reported in December 2019 in Wuhan, the capital city of Hubei Province in central China. The disease within a very short time crossed the geographical boundaries across the world with a doubling of epidemic size every week in geometric progression. By the 15th of September 2020, more than 29.1 million cases and 922252 confirmed deaths have been reported across 216 countries and territories 2 . The western countries are the most affected, with over $50 \%$ of cases and $60 \%$ of deaths reported in the Europe region 3.

On 23rd January 2020, Nepal confirmed the first COVID case in a 31-year-old student who had arrived in Kathmandu on 9 January from Wuhan, China. This was also claimed to be the first reported case in South Asia. The number of cases has tremendously increased in Nepal, and by 15 September 2020, the Ministry of Health and Population (MoHP) has confirmed a total of 55,329 cases and 360 deaths in the country4. The cases are still increasing in Nepal.

The common symptoms of COVID-19 are flulike features, including fever, dry cough, fatigue, breathing difficulties, and hyposmia or anosmia. Pneumonia and acute respiratory distress syndrome are seen among the complicated cases. The old age and patients with pre-existing medical conditions, including diabetes, hypertension, cancer, heart, lung, and renal diseases, have been noticed as potential risk factors for severe disease and mortality. However, complicated cases are not uncommon in children adults5-6.

The rapid spread of SARS-CoV-2 is due to human-to-human transmission and indirect contact with 
contaminated objects. It is transmitted through body fluid aerosols from the mouth or nose of the infected person during coughs, sneezes, and talks. SARS-CoV-2 remains intact and contagious in droplets suspended in the air for up to three hours and when it settles on objects, remain there for hours to days. Such contaminated objects, when touched and made contact with eyes, nose, or mouth, an individual can become infected7.

The incubation period ranges from 2 to 14 days, but often the symptoms appear on around five days. The standard diagnosis of COVID-19 is typically made by Reverse transcription-polymerase chain reactionbased SARS-CoV-2 RNA detection testing of a nasopharyngeal swab. Based on the clinical presentation, the COVID-19 patients classified as Asymptomatic- COVID nucleic acid test positive. Without any clinical symptoms and signs and the chest imaging is normal; Mild- Symptoms of acute upper respiratory tract infection (fever, fatigue, myalgia, cough, sore throat, runny nose, sneezing) or digestive symptoms (nausea, vomiting, abdominal pain, diarrhea); ModeratePneumonia (frequent fever, cough) with no obvious hypoxemia, chest CT with lesions; Severe- Pneumonia with hypoxemia (SpO2 <92\%); and Critical- Acute respiratory distress syndrome (ARDS), may have a shock, encephalopathy, myocardial injury, heart failure, coagulation dysfunction, and acute kidney injury8-9.

Structurally, SARS-CoV-2 is a single-stranded RNA virus, positive-sense, enveloped, with a diameter of $60 \mathrm{~nm}$ to $140 \mathrm{~nm}$ and unique spikes with sizes $9 \mathrm{~nm}$ to $12 \mathrm{~nm}$, giving the appearance of a solar corona10.

Its pathophysiology includes a distinctive life cycle and host response. Life-cycle begins with the binding of the viruses to host receptors (attachment). Then through endocytosis or membrane fusion, they enter host cells (penetration). The viral RNA utilizes the nucleus of the host for replication so that viral mRNA is used to make viral proteins (biosynthesis). Finally, the new viral particles are made (maturation) and released. SARS-CoV-2 binds to the angiotensin-converting enzyme 2 (ACE2) receptor of the target cells (nasal and bronchial epithelial cells and pneumocytes) through the viral structural spike (S) protein. The transmembrane serine protease type 2 (TMPRSS2) of the host cell facilitates viral uptake by cleaving ACE2 and activating the SARS-CoV-2 S protein, which mediates coronavirus entry into host cells11. The host Target cells, especially alveolar epithelial type II, express both ACE2 and TMPRSS2.12.

SARS-CoV-2 infects and kills T-cells, impairs lymphopoiesis, and enhances lymphocyte apoptosis, causing marked lymphopenia, coupled with the viral inflammatory response debilitating both the innate and the acquired immune response. Finally, the viral load rises by accelerated replication and spread to pulmonary capillary endothelial cells by endothelial barrier disruption, accentuating the inflammatory response, and triggering an influx of monocytes and neutrophils. Due to the infiltration of monocytes and neutrophils and intense viral inflammatory host response along with the Bradykinin-dependent lung angioedema, the interstitial edema develops. This is responsible for acute respiratory distress syndrome (ARDS) in earlyphase13.

The monocyte infiltration, along with edema, appears as characteristic ground-glass opacities on computed tomographic imaging of the chest. The edema, along with the disrupted endothelial barrier, leads to difficult alveolar-capillary oxygen transmission and severely reduced oxygen diffusion capacity across the respiratory membrane. This causes an acute fall in SPO2\%, a characteristic feature of COVID-19. The endothelial damage, along with intense inflammation of lung tissues and surroundings, is responsible for high activation of platelets starting massive coagulation, consumption of clotting factors, intravascular coagulation, micro thrombi formation with its complications like limb ischemia, ischemic stroke, myocardial infarction, renal and multi-organ failures in severe COVID-19 cases 14 .

To date, the specific vaccine with safety and efficacy against SARS-CoV-2 has not been developed through many scientists in the world working day and night on it. Moreover, there is no known specific antiviral drug, so the primary treatment is still symptomatic only 15.

Nepal has implemented preventive guidelines recommended by $\mathrm{WHO}$ to protect human to human transmission of COVID-19 included social distancing, ban on public gathering including religious gatherings, regular personal hygiene with soap hand washing and use of hand sanitizers; use of face masks, respiratory hygiene to cover the mouth and nose while sneezing or coughing, one or two passengers per seat in public vehicles, temporary closing of public places, cities, schools, and colleges 16 .

However, the success of these measures was variable and largely affected by socio-economic factors and knowledge and attitude of the people in different areas of the nation.

Although every sector closed temporarily, the closing of health sectors could be very unnatural and impossible. Health care workers have to work day and night in hospitals without any break. Moreover, the hospital zone falls in the red zone for the transmission of COVID-19. Healthcare workers stand at the frontlines to investigate and manage COVID-19 patients, and they are at high risk of being infected with Coronavirus. They are already stressed due to fear of pathogen exposure, long working hours, psychological distress, and fatigue, and sometimes with occupational burnout and stigma, and physical violence. At the same time, the health workers of Nepal have to work with very minimum 
facilities and insufficient personal protection equipment and without health and wealth insurance, especially in private health sectors, which occupy more than 70 percent of health services in Nepal. Therefore, health workers, especially in developing countries like Nepal, are more in distress from all aspects, including health, wealth, and social insecurity. The health workers should know about COVID-19 with a positive attitude and very safe practice from hospital to home. Many studies have been reported regarding knowledge, attitude, and practice of health workers towards COVID-19 but a limited number of them mentioned the background conditions where the health workers work with poor health facilities, low socio-economic, social stigma, and neglect and without health wealth and social security like in Nepal. They are bankrupt not only financially but socially and emotionally. With this background, it is important to assess the knowledge, attitude, risk, and fear among health professionals towards COVID-19 and to evaluate their satisfaction at local and governmental policies made to promote positive preventive and therapeutic practices and to avert negative attitudes.

\section{Methods}

A questionnaire-based descriptive crosssectional study was conducted among health professionals working at Chitwan Medical College, a tertiary care teaching hospital in Mid-Nepal. A convenience non-probability sampling technique was used to select the participants to collect the data ensuring their confidentiality precautions. A selfadministered questionnaire that could investigate the objectives of the study in our setup and population were adapted after reviewing methodologies of some relevant published researches17-19 and COVID-19 websites of WHO, Ministry of Health and Population (MOHP), Nepal and COVID-19 facts web page of Chit wan Medical College.

The items in the questionnaire were checked and validated for content and relevance of the study. Further, the pilot study was done on 20 participants to intend the validity of items in the questionnaire. The Cronbach's alpha reliability test, revealed a value of 0.8 $(x 2=1762.5, p=0.001)$, was applied to measure the internal consistency of all items in the questionnaire.

Excluding the participants' sociodemographic variables such as age, gender, and occupation, the questionnaire included a total of 40 statements or items displayed into four categories: the category 1 assessed the participant's knowledge about COVID-19 in the pandemic era, including its clinical presentation, mode of transmission, prevention and treatment outcome. Category 2 measured the risk perception and attitude of participants. Category 3 assessed the fears of healthcare workers at working place, and category 4 brought attention to stakeholders about how to encourage healthcare workers to allay their fears and promote positive preventive and therapeutic practices. The participants were asked to address their responses to each statement using a combination of YES-NO and Likert scale rating kept at the end of every statement.

In the partial lockdown condition, the data from the participants collected both by direct distribution of questionnaire on printed papers with maintaining social distancing and online distribution of the questionnaire through Google form, whichever was convenient and feasible. The link for the online version of the questionnaire was sent to participants via email and what apps. Google form questionnaire was assessable by participants going through the provided link but only at once to prevent the duplication of the data by the same participant. The remaining participants filled the questionnaire distributed in paper form following one on one method with proper precaution and using mask and hand sanitizer. The completed form was collected immediately. All the participants of the study were health Professionals from CMC, including doctors, nurses, and medical laboratory staff. The purpose of the study was informed well to all participants.

All the participants were assured of the confidentiality of their information stating that data would be used for research purposes only. This was voluntary participation, and informed written consent was taken from all participants before filling the questionnaire. The participants' responses from the online version were retrieved and saved in Microsoft Excell. The data from paper responses were also entered into the same file. After that, the collected data were processed on SPSS version 21, Armonk, Newyork, the USA, for the data analysis using descriptive statistics.

The research approval of this study was obtained from the Institutional Review Committee of Chitwan Medical College (CMC-IRC), Nepal.

\section{Result}

This study included 150 (male-44\% and female$56 \%$ ) health professionals with a mean age of 26.14 \pm 6.092 years working at CMCTH, Nepal. The health professionals participated in this study were medical officer/intern (36.7\%), specialist/consultant (13.3\%), nurses (40.7\%), and laboratory staffs (9.3\%) (Table 1). This questionnaire-based survey revealed that many health professionals (54.7\%) acquire the information regarding the COVID-19 pandemic through online news and social media like WhatsApp, Facebook and the remaining $45.7 \%$ via combined sources including national and international news on TV, WHO and government health media (Ministry of Health and population, MOHP), Nepal (Table 2). 
Table 1: Demographic characteristics of the participants $(\mathrm{N}=150)$

\begin{tabular}{|c|c|c|}
\hline \multicolumn{2}{|c|}{ Variables } & Frequency (\%) \\
\hline \multirow{2}{*}{ Sex } & Male & $66(44)$ \\
& Female & $84(56)$ \\
\hline \multirow{4}{*}{ Qualification } & Medical officer/intern & $55(36.7)$ \\
& Specialist/consultant & $20(13.3)$ \\
& Nurse & $61(40.7)$ \\
& Laboratory staff & $14(9.3)$ \\
\hline
\end{tabular}

Regarding the participant's knowledge about presentation, mode of transmission, prevention, and COVID-19, most health professionals were well aware of the COVID-19 pandemic, including its clinical

treatment outcome (Tables 2a and 2b).

Table 2a: The participant's knowledge about COVID-19 in the pandemic era, including its clinical presentation, mode of transmission, prevention, and treatment outcome

\begin{tabular}{|c|c|c|c|c|}
\hline \multirow[b]{2}{*}{ S.N. } & \multirow{2}{*}{$\begin{array}{c}\text { Variables } \\
\text { (Statements of questionnaire) }\end{array}$} & \multicolumn{3}{|c|}{ Responses $(\mathrm{N}=150)$} \\
\hline & & $\begin{array}{l}\text { Yes } \\
\mathrm{n}(\%)\end{array}$ & $\begin{array}{c}\text { No } \\
\mathrm{n}(\%)\end{array}$ & $\begin{array}{c}\text { Not sure } \\
\mathrm{n}(\%)\end{array}$ \\
\hline 1. & $\begin{array}{l}\text { Source of information } \\
\text { 1. Social media and online news (WhatsApp, } \\
\text { Facebook) } \\
\text { 2. Combined sources (TV news, WHO, MOHP, } \\
\text { in urnals etc.) }\end{array}$ & \multicolumn{3}{|c|}{$\begin{array}{l}82(54.7) \\
68(45.3)\end{array}$} \\
\hline 2. & Date of first confirmed COVID case in Nepal & $92(61.3)$ & $58(38.7)$ & - \\
\hline 3. & $\begin{array}{l}\text { Total number of confirmed cases of COVID-19 } \\
\text { by } \mathrm{MOH}, \mathrm{Nepal} \text { as at } 15 \text { th Sept, } 2020\end{array}$ & $89(59.3)$ & $22(14.7)$ & $39(26.0)$ \\
\hline 4. & $\begin{array}{l}\text { The age group mostly affected by COVID-19 in } \\
\text { Nepal }\end{array}$ & $137(91.7)$ & - & $13(8.7)$ \\
\hline 5. & COVID- caused by virus & $150(100)$ & - & - \\
\hline 6. & Started from Wuhan City, China & $150(100)$ & - & - \\
\hline 7. & Incubation period is up to 2 wks. & $117(78)$ & - & $33(22)$ \\
\hline 8. & It is an aerosol infection & $150(100)$ & - & - \\
\hline 9. & Transmitted rapidly from human to human & $150(100)$ & - & - \\
\hline 10. & If infected death is sure & - & $85(56.7)$ & 65 (43.3) \\
\hline 11. & $\begin{array}{l}\text { Infection can be confirmed without laboratory } \\
\text { test }\end{array}$ & & $118(78.7)$ & $32(21.3)$ \\
\hline 12. & Treatment is possible & & 125(83.3\%) & $25(16.7)$ \\
\hline
\end{tabular}

They all (150, 100\%) mentioned that COVID-19 is a viral disease, originated from Wuhan city, China, transmitted rapidly through air droplets from one person to another person. The majority of the participants (117, $78 \%$ ) reported the incubation period of SARS COV-2 up to 14 days, while 33 (22\%) were unsure about the incubation period. A high proportion of participants (78.7\%) reported that the confirmation of the disease requires the laboratory test, while $21.3 \%$ was not sure about the confirmation. Interestingly, $56.7 \%$ of participants said that death is not imminent after SARS COV-2 infection, and $43.3 \%$ was not sure about it. Moreover, most of them (83.3\%) said 'NO' to the possibility of treatment, and $25(16.7 \%)$ were not sure of its treatment. Over 59\% of participants knew the total number of confirmed COVID-19 cases in Nepal on 15th September 2020, whereas 39 (26\%) were unsure about the total case. Ninety-two (61.3\%) participants knew the 
date of the first confirmed COVID case in Nepal, and the remaining $58(38.7 \%)$ didn't know the exact date of the first case in Nepalese. A very high proportion (91.7\%) knew the age group most affected by COVID-19 in Nepal, whereas $8.7 \%$ was unsure.

Table 2b: The participant's knowledge about COVID-19 in the pandemic era, including its clinical presentation, mode of transmission, prevention, and treatment outcome

\begin{tabular}{|c|c|c|c|c|c|c|}
\hline \multirow[b]{2}{*}{$\begin{array}{l}\text { S. } \\
\text { N. }\end{array}$} & \multirow[b]{2}{*}{$\begin{array}{l}\text { Variables } \\
\text { (Statements of questionnaire) }\end{array}$} & \multicolumn{5}{|c|}{ Responses $(\mathrm{N}=150)$} \\
\hline & & $\begin{array}{l}\text { Strongly } \\
\text { agree } \\
\mathrm{n}(\%)\end{array}$ & $\begin{array}{l}\text { Agree } \\
\mathrm{n}(\%)\end{array}$ & & & $\begin{array}{l}\text { Disagre } \\
\text { e }(\%)\end{array}$ \\
\hline 1. & $\begin{array}{l}\text { Clinical presentation includes: Fever }>38^{\circ} \mathrm{C} \text {, Dry } \\
\text { cough, Difficulty in breathing, Fatigue, Nasal } \\
\text { congestion, Nausea, Diarrhea, Sneezing, Mayalgia }\end{array}$ & $114(76)$ & $36(24)$ & & & - \\
\hline 2. & COVID spread is preventable & 107 (71.3) & $43(28.7)$ & & & \\
\hline 3. & $\begin{array}{l}\text { The following can reduce the spread of COVID-19. } \\
\text { (Tick all that apply). } \\
\text { a. The use of face masks } \\
\text { b. } \quad \text { Restriction of movement through lock } \\
\text { down/stay at home } \\
\text { c. } \quad \text { Restriction of crowding through social } \\
\text { distancing } \\
\text { d. } \quad \text { Environmental sanitation } \\
\text { e. } \\
\text { f. } \quad \text { Using hand sanitizer }\end{array}$ & \multicolumn{5}{|c|}{$150(100)$} \\
\hline 4. & $\begin{array}{l}\text { To prevent the infection by COVID-19, individuals } \\
\text { should avoid going to crowded places such as bus } \\
\text { parks and avoid taking public transportations. }\end{array}$ & $139(92.7)$ & $11(7.3)$ & - & & - \\
\hline 5. & $\begin{array}{l}\text { Isolation and treatment of people who are infected } \\
\text { with the COVID- } 19 \text { virus are effective ways to reduce } \\
\text { the spread of the virus. }\end{array}$ & $137(91.7)$ & $13(8.7)$ & - & & - \\
\hline 6. & $\begin{array}{l}\text { Contact tracing and observation in isolation for } 14 \\
\text { days is important step to prevent spread to public }\end{array}$ & $131(87.3)$ & $\begin{array}{c}19 \\
(12.7)\end{array}$ & - & & - \\
\hline 7. & COVID-19 is treatable although mainly supportive? & $132(88)$ & $18(12)$ & & & \\
\hline 8. & $\begin{array}{l}\text { It is not necessary for children and young adults to } \\
\text { take measures to prevent the infection by the COVID- } \\
19 \text { virus. }\end{array}$ & - & - & - & 150 & 00) \\
\hline
\end{tabular}

All the health professionals participated in this study were well accepted (76\% strongly agree and $24 \%$ agree) to the statement with the flue like the clinical presentation of COVID-19 including high Fever > 380C, persistent dry cough, sneezing, difficulty in breathing, fatigue, malaise, nasal congestion, nausea, diarrhea (Table 2b). They all agreed (strongly agree- $71.3 \%$ and agree-28.7\%) that the COVID spread is quite preventable. Moreover, every participant (150, 100\%) strongly agreed to the ways to reduce the transmission of COVID-19, including use of face masks, restriction of movement through lockdown/stay at home, restriction of crowding through social distancing, environmental sanitation, regular hand washing with detergent and frequent use of hand sanitizer. Additionally, 92.7\% strongly agreed, and $7.3 \%$ agreed that individuals should avoid crowded places such as bus parks and avoid taking public transportations. Almost all participants highly rated the prompt isolation and treatment (Strongly agree-91.7\% and agree- $8.3 \%$ ) of the confirmed case followed by contact tracing and observation (Strongly agree-87.3\% and agree-12.7\%) for 14 days to prevent transmission to the general mass. They know (Strongly agree-88\% and agree-12\%) that the specific treatment for COVID-19 is not available, though only supportive management is possible. All the participants (Disagree-100\%) rated against the statement indicating the children and young need not to take preventive measures (Table $2 \mathrm{~b}$ ). 
Table 3: The participant's ( $N=150)$ risk perception and attitude towards COVID-19

\begin{tabular}{|c|c|c|c|c|c|}
\hline \multirow[b]{2}{*}{ S.N. } & \multirow[b]{2}{*}{$\begin{array}{l}\text { Variables } \\
\text { (Statements of questionnaire) }\end{array}$} & \multicolumn{4}{|c|}{ Responses $(\mathrm{N}=150)$} \\
\hline & & $\begin{array}{c}\text { Strongly } \\
\text { agree } \\
n(\%)\end{array}$ & $\begin{array}{l}\text { Agree } \\
\mathrm{n}(\%)\end{array}$ & $\begin{array}{l}\text { Not sure } \\
\mathrm{n}(\%)\end{array}$ & $\begin{array}{l}\text { Disagree } \\
\mathrm{N}(\%)\end{array}$ \\
\hline 1. & $\begin{array}{l}\text { I see myself and my family at risk of infection from } \\
\text { going to work at hospital these days. }\end{array}$ & $132(88)$ & $18(12)$ & - & - \\
\hline 2. & $\begin{array}{l}\text { Health workers are more prone to having the } \\
\text { infection. }\end{array}$ & $150(100)$ & - & - & - \\
\hline 3. & $\begin{array}{l}\text { There is no known risk in coming in contact with a } \\
\text { COVID-19 patient. }\end{array}$ & - & - & - & $150(100)$ \\
\hline 4. & $\begin{array}{l}\text { My willingness to go to work has greatly affected by } \\
\text { COVID-19 pandemic. }\end{array}$ & $130(86.7)$ & 20 (13.3) & - & - \\
\hline 5. & $\begin{array}{l}\text { How many days in a week do you go to work since } \\
\text { the beginning of the pandemic? }\end{array}$ & \multicolumn{4}{|c|}{0 day- 43 (28.7\%), 3 days- 80 (53.3\%), 6 days- 27 (18\%) } \\
\hline 6. & $\begin{array}{l}\text { How many days in a week do you normally go to } \\
\text { work before this time? }\end{array}$ & \multicolumn{4}{|c|}{6 days- 150 (100\%) } \\
\hline 7. & $\begin{array}{l}\text { If you are adequately compensated, will you be } \\
\text { willing to attend to COVID - } 19 \text { patients. }\end{array}$ & - & $74(49.3)$ & $65(43.3)$ & $11(7.3)$ \\
\hline
\end{tabular}

On the assessment of the participant's risk perception and attitude towards COVID-19, the majority of them (88\%) were afraid of going to work in a hospital, and they $(100 \%)$ also highly rated that health workers being more prone to get infected (Table 3). They all disagreed with the statement -there is no known risk in coming in contact with a COVID-19 patient. Their willingness to work in a hospital has greatly affected them. They work fewer days (28.7\%-0 day, 53.3\%-3 days) in a week these days than they were working (6days/wk-100\%) before the pandemic. Almost half of the participants (49.3\%) agreed to work for COVID patients if they were adequately compensated. However, $43.3 \%$ of participants were not sure, and $7.3 \%$ completely disagreed with attending such patients even after compensation.

Table 4: Fear of Healthcare Workers to Covid-19 in the perspective of workplace, local, and national policy

\begin{tabular}{|c|c|c|c|c|c|}
\hline \multirow[b]{2}{*}{ S.N. } & \multirow[b]{2}{*}{$\begin{array}{l}\text { Variables } \\
\text { (Statements of questionnaire) }\end{array}$} & \multicolumn{3}{|c|}{ Responses $(\mathrm{N}=150)$} & \multirow[b]{2}{*}{$\begin{array}{l}\text { Disagree } \\
\mathrm{N}(\%)\end{array}$} \\
\hline & & $\begin{array}{c}\text { Strongly } \\
\text { agree } \\
\text { n (\%) }\end{array}$ & $\begin{array}{c}\text { Agree } \\
\mathrm{n}(\%)\end{array}$ & $\begin{array}{l}\text { Not sure } \\
\mathrm{n}(\%)\end{array}$ & \\
\hline 1. & Work place Safety is adequate & - & $15(10)$ & $65(43.3)$ & $11(7.3)$ \\
\hline 2. & $\begin{array}{c}\text { Lack of social insurance policy for health care } \\
\text { workers is an obstacle to effective service delivery } \\
\text { especially in this period of the pandemic. }\end{array}$ & $106(70.7)$ & $33(22)$ & $11(7.3)$ & - \\
\hline 3. & Hospital infection control policy is adequate. & - & $39(26)$ & $75(50)$ & $36(24)$ \\
\hline 4. & $\begin{array}{l}\text { There is the possibility of getting the infection in the } \\
\text { hospital. }\end{array}$ & $90(60)$ & $57(38)$ & $3(2)$ & - \\
\hline 5. & $\begin{array}{c}\text { Adequate surveillance policy has been put in place } \\
\text { by the Government. }\end{array}$ & - & $4(2.7)$ & $29(19.3)$ & $117(78)$ \\
\hline 6. & Adequate testing centers and contact tracing. & - & - & $11(7.3)$ & $\begin{array}{c}139 \\
(92.7) \\
\end{array}$ \\
\hline 7. & $\begin{array}{c}\text { Testing of temperature with infrared thermometer at } \\
\text { the entrance to the hospital is adequate screening } \\
\text { exercise. }\end{array}$ & - & $21(14)$ & $49(32.7)$ & $80(53.3)$ \\
\hline
\end{tabular}


Fear of health workers to COVID-19 amid the present facility at the workplace, local, and national policy are essential parts of an assessment in this study (Table 4). Overall, the health workers $(65 \%)$ rated that workplace safety is not adequate. They (50\%- not sure, $24 \%$-disagree) were not in favor of adequate hospital infection control. Additionally, a large number (60\%strongly agree, $57 \%$-agree and $2 \%$-not sure) mentioned that they afraid of being infected in the hospital. They (70\%-strongly agree, 22\%-agree) strongly pointed out the failure of the national and local policy to uplift the social insurance policy, which is a great obstacle to work effectively in this pandemic. The highly-rated government of Nepal has failed to expand adequate testing centers (92.7\%- disagreed) approachable to every community and contact tracing (53.3\%-disagreed and $32.7 \%-$ not sure). They also do not believe that testing of temperature with an infrared thermometer at the entrance to the hospital is an adequate screening exercise (53.3\%-disagree and 32.7\%-not sure) (Table 4).

Table 5: The perspective of participants $(N=150)$ regarding Local and governmental facilities to encourage HealthCare Workers to subside their risks and fears

\begin{tabular}{|c|c|c|c|}
\hline \multirow[b]{2}{*}{ S.N. } & \multirow{2}{*}{$\begin{array}{c}\text { Variables } \\
\text { (Statements of questionnaire) }\end{array}$} & \multicolumn{2}{|c|}{ Responses $(\mathrm{N}=150)$} \\
\hline & & $\begin{array}{c}\text { Yes } \\
\mathrm{n}(\%)\end{array}$ & $\begin{array}{c}\text { No } \\
\mathrm{n}(\%)\end{array}$ \\
\hline 1. & $\begin{array}{l}\text { Provision of Personal Protective Equipment (PPE) to all staffs working in } \\
\text { direct contact with all patients. }\end{array}$ & $115(76.7)$ & $35(23.3)$ \\
\hline 2. & Good stimulus package. & $19(12.7)$ & $\begin{array}{c}131 \\
(87.3)\end{array}$ \\
\hline 3. & Impressive life and social insurance policy & $6(4)$ & $144(96)$ \\
\hline 4. & Strengthening disease surveillance & $26(17.3)$ & $\begin{array}{c}124 \\
(82.7)\end{array}$ \\
\hline 5. & Train and retrain of heath care personnel & $52(34.7)$ & $98(65.3)$ \\
\hline 6. & $\begin{array}{c}\text { Facilities to health workers in private sector less than the government } \\
\text { sector }\end{array}$ & $125(83.3)$ & $25(16.7)$ \\
\hline
\end{tabular}

Health safety and security, along with proper encouragement to health professionals, is the fundamental realm to fight against the COVID pandemic. Therefore, assessing the perspective of participants regarding Local and governmental facilities to encourage HealthCare Workers to subside their risks and fears becomes important in this study (Table 5). The majority of the participants $(76.7 \%)$ said there is a provision of Personal Protective Equipment (PPE) to all staff working directly with all patients. However, 23.3\% still mentioned Personal Protective Equipment (PPE) to all staff is not available. Most of them (87.3\%) are not aware of a good stimulus package either by the local hospital or by the government of Nepal. Almost all (96\%) rated 'NO' to impressive life and social insurance policy either by local or government buddy. The majority of participants mentioned no proper strengthening disease surveillance (82.7\%) and no provision of adequate training and retraining of health care personnel (65.3\%) at the local or government level. Similarly, a high rating (83.3\%) is made to the statement that there are more facilities for health professionals working in the government sector.

\section{Discussion}

COVID-19 pandemic has created most panic situations to the human race globally, affecting progress and existence, social activities, education, and health services. Although every sector closed temporarily, the closing of health sectors would be unnatural, inhumane, and impossible 20. Health care workers, the front liners to fight against COVID, work day and night in the hospitals without any break. They are at high risk of getting infected, thus already stressed due to fear of pathogen exposure, long working hours, psychological distress, and fatigue and sometimes with occupational burnout and stigma, and physical violence 21. Moreover, the health workers of Nepal have to work with very minimum facilities and insufficient personal protection equipment and without health and wealth safety and security. Therefore, this study included 150 health professionals at CMCTH to assess their Knowledge, Attitude, risk, and fear towards Covid-19 and also to evaluate the level of their encouragement from the perspective of workplace, local, and national policy. The health professionals who participated in this study were medical officer/intern, specialist/consultant, 
nurses, and laboratory staff, among which nurses were the largest in number. Similar to the study by Ronald Olum et al22, our study revealed that most of the health professionals acquire the COVID-19 health information through online news and social media like WhatsApp, Facebook and rest via combined sources including national and international news on TV, WHO and government health media (Ministry of Health and population, MOHP), Nepal.

Regarding the participant's knowledge about COVID-19, most of the health professionals were well aware of the disease, including its clinical presentation, mode of transmission, prevention and treatment outcome, and their scenario in Nepal. They all mentioned that COVID-19 is a viral disease, originated from Wuhan city, China, transmitted rapidly through air droplets from human to human. A high proportion of participants reported that the confirmation of the disease requires the laboratory test and the incubation period is up to two weeks. Interestingly, $56.7 \%$ of participants said that death is not imminent after SARS COV-2 infection, and $43.3 \%$ was not sure about it. These findings are incoherence with the study by Bhagvathula AS et al 23, except there was a higher percentage of the rating for the statement - death is not imminent after COVID.

All the participants have a good knowledge regarding the clinical presentation of COVID-19, including flu-like symptoms with high Fever $>380 \mathrm{C}$, persistent dry cough, sneezing, difficulty in breathing, fatigue, malaise, nasal congestion, nausea, diarrhea. They all agreed that the COVID spread is quite preventable. Further, they knew well about the established preventive measures of COVID-19 to reduce the spread, including proper use of face masks, restriction of movement through lockdown/stay at home, restriction of crowding through social distancing, avoid public transports, environmental sanitation, regular hand washing with detergent and frequent use of hand sanitizer. Almost all participants highly rated the prompt isolation and treatment (Strongly agree-91.7\% and agree- $8.3 \%$ ) of the confirmed case followed by contact tracing and observation (Strongly agree-87.3\% and agree-12.7\%) for 14 days to prevent transmission to the general mass. They know (Strongly agree-88\% and agree-12\%) that the specific treatment for COVID-19 is not available, though only supportive management is possible. All the participants (Disagree-100\%) rated the statement indicating the children and young need not to take preventive measures. These findings of clinical presentation, prevention, and management are consistent with the report made by Ronald et al 22 . However, the KAP survey among US residents 24 (80\%) revealed less than those (91-100\%) in our study. Further, the study 25 involving the general population in China scored high, similar to our study.
Often, the knowledge of a person reflects the attitude and practices provided with the sound environment. On assessing the participant's risk perception and attitude towards COVID-19, the majority of them (88\%) were afraid of going to work in the hospital, and they (100\%) also highly rated that health workers have a high chance to get infected. This fear hurts their willingness to go to work in the hospital, and their working days in a week have greatly affected (28.7\%-0 day, 53.3\%-3 days). These fear perceptions are in line with findings of Zhou et al26 and Maleki et al27 reporting that $85 \%$ and $92 \%$ of health workers, respectively, were afraid of COVID infection and transmitting it to the family.

They strongly disagreed with the statement there is no known risk in coming in contact with a COVID-19 patient. However, almost half of the participants (49.3\%) agreed to work for COVID patients if they were adequately compensated. Meanwhile, $43.3 \%$ of participants were not sure, and $7.3 \%$ completely disagreed with attending such patients even after sound compensation. These findings are comparable to Egarra-Valdivia et al 28, stating that the fear of healthcare workers towards the COVID-19 pandemic is reinforced by inadequate workplace safety without profound compensation and encouragement.

Regarding the facility at the workplace, local and national policy, most participants expressed a high level of dissatisfaction in our study. More than two-thirds of the participants mentioned that workplace safety4 and hospital infection control, including testing temperature with an infrared thermometer, are inadequate. They (70\%-strongly agree, 22\%-agree) strongly pointed out the failure of the national and local policy to uplift the social insurance policy, which is a great obstacle to work effectively in this pandemic. Further, they expressed that the government of Nepal has failed to expand adequate testing centers (92.7\%disagreed) approachable to every community and contact tracing (53.3\%-disagreed and $32.7 \%$ - not sure). These findings are in line with the report by Ogolodom MP29. In contrast to our study, previous studies30-32 mentioned a high level of preventive measures and safety were taken into account to encourage health workers and battle against the common enemy of the world, COVOD-19.

The assessment of the perspective of participants regarding Local and governmental facilities to encourage Health Care Workers to subside their risks and fears becomes important in this study. Like previous studies 33-34 majority of the participants (76.7\%) in this study said there is a provision of Personal Protective Equipment (PPE) to all staff working in direct contact with all patients. However, $23.3 \%$ still mentioned Personal Protective Equipment (PPE) to all staff is not available. Most of them (87.3\%) are not aware of a good 
stimulus package either by the local hospital or by the government of Nepal. Almost all (96\%) rated 'NO' to impressive life and social insurance policy either by local or government buddy. The majority of participants mentioned no proper strengthening disease surveillance $(82.7 \%)$ and no provision of adequate training and retraining of health care personnel $(65.3 \%)$ at the local or government level. Similarly, a high rating $(83.3 \%)$ is made to the statement that there are more facilities for health professionals working in the government sector. Health safety and security, along with proper encouragement to health professionals, is the fundamental realm to fight against the COVID pandemic35. The risk of reporting increased positive case for COVID-19 among front-line health-care workers could be reduced by Health-care systems by ensuring adequate availability of PPE and develop additional strategies to protect health-care workers from COVID19. 35

The intensive work drained health-care providers not only financially but also physically and emotionally. Health-care workers showed their resilience and the spirit of professional dedication to overcome difficulties. Comprehensive support should be provided to safeguard the well-being of health-care providers. Regular and intensive training for all health-care providers is necessary to promote preparedness and efficacy in crisis management36.

The limitation of this study could be the fewer number of participants and less involvement of a diverse group of Health faculties/workers from different hospitals in this region. Further, a better tool than this questionnaire could be used to assess their knowledge, attitude, and fear and risk perception to COVID-19 and their opinion to amend local and national health policy.

\section{Conclusion}

Health professionals bear adequate knowledge regarding clinical presentation, mode of transmission, established prevention strategies and treatment outcome, and their scenario in Nepal. However, due to inadequate hospital work safety, poor infection control, lack of standard local and governmental strategies to empower financial, social, and health security to health care providers, most health professionals have lost their motivation to go to work in a hospital. These factors not only has limited their working days in a week but also heightened their fear and risk perceptions to COVID-19. Beyond these, our study also revealed that comprehensive support should be aligned for the wellbeing and safeguard of health-care providers. The standard policies should be made to provide regular and intensive training for all health-care providers and boost them emotionally and socially to promote preparedness and efficacy in crisis management to promote positive preventive and therapeutic practices and to avert negative attitudes.
Disclosure: No conflicts of interest.

Funding: None

\section{AcknOWledgment}

We thank all the participants for their cooperation in this study. We acknowledge CMC-IRC, Chitwan Medical College, for providing ethical clearance of this study.

\section{References Références Referencias}

1. Wang, C.; Horby, P. W.; Hayden, F. G.; Gao, G. F. A novel coronavirus outbreak of global health concern. Lancet. 2020, 395, 470-473. [CrossRef]

2. World Health Organisation. Coronavirus disease 2019 (COVID-19) Situation Report - weekly update. Geneva: WHO. (2020). Available online at: www.who.int/ emergencies/diseases/novelcoronavirus-2019/situation-reports (accessed September 15, 2020).

3. World Health Organisation. Coronavirus disease 2019 (COVID-19) Situation Report. Geneva: WHO. (2020). Available online at: www.who.int/emerge ncies/diseases/novel-coronavirus-2019/situation-rep orts (accessed September 15, 2020).

4. COVID-19 report dashboard 14 September 2020. Ministry of Health and Population (Nepal)| language. https://covid19.mohp.gov.np/. (accessed September 15, 2020).

5. Lotfi M, Hamblin MR, Rezaei N. COVID-19: transmission, prevention, and potential therapeutic opportunities. Clin Chim Acta. 2020; 508: 254-266. doi:10.1016/j.cca.2020.05.044

6. Lechien JR, Chiesa-Estomba CM, De Siati DR, et al. Olfactory and gustatory dysfunctions as a clinical presentation of mild-to-moderate forms of the coronavirus disease (COVID-19): a multicenter European study. Eur Arch Otorhinolaryngol. 2020; 277 (8): 2251-2261. doi:10.1007/s00405-02005965-1

7. van Doremalen $\mathrm{N}$, Bushmaker $\mathrm{T}$, Morris $\mathrm{DH}$, et al. Aerosol and surface stability of SARS-CoV-2 as compared with SARS-CoV-1. N Engl J Med. 2020; 382(16): 1564-1567. doi:10.1056/NEJMc2004973

8. Dong Y., Mo X., Hu Y., Qi X., Jiang F., Jiang Z., Tong S. Epidemiological characteristics of 2143 Pediatric patients with 2019 coronavirus disease in China. Journal. 2020 doi: 10.1542/peds.2020-0702.

9. Cascella M, Rajnik M, Cuomo A, Dulebohn SC, DiNapoli R. Features, evaluation and treatment coronavirus (COVID-19) [Updated 2020 Apr 6]. In: Stat Pearls [Internet]. Treasure Island, FL: Stat Pearls Publishing (2020).

10. Goldsmith CS, Tatti KM, Ksiazek TG, et al. Ultra structural characterization of SARS coronavirus. Emerg Infect Dis. 2004; 10(2): 320-326. doi:10.3201/eid1002.030913 
11. Hoffmann M, Kleine-Weber $H$, Schroeder S, et al. SARS-CoV-2 cell entry depends on ACE2 and TMPRSS2 and is blocked by a clinically proven protease inhibitor. Cell. 2020; 181(2): 271-280. doi:10.1016/j.cell.2020.02.052

12. SungnakW, Huang N, Becavin $\mathrm{C}$, et al; HCA Lung Biological Network. SARS-CoV-2 entry factors are highly expressed in nasal epithelial cells together with innate immune genes. Nat Med. 2020; 26(5): 681-687. doi:10.1038/s41591-020-0868-6

13. van de Veerdonk FL, Netea MG, van Deuren M, et al. Kallikrein-kinin blockade in patients with COVID19 to prevent acute respiratory distress syndrome. Elife. Published online April 27, 2020. doi:10. 7554/eLife. 57555

14. Goldsmith CS, Tatti KM, Ksiazek TG, et al. Ultra structural characterization of SARS coronavirus. Emerg Infect Dis. 2004; 10(2): 320-326. doi:10.3201/eid1002.030913

15. Centers for Disease Control and Prevention (CDC). Interim Clinical Guidance for Management of Patients with Confirmed Coronavirus Disease (COVID-19). Updated Sept. 10, 2020. (accessed September 15, 2020).

16. Interim Clinical Guidance for Management of Patients with Confirmed Coronavirus Disease (COVID-19)". Centers for Disease Control and Prevention. 4 April 2020. Archived from the original on 2 March 2020. Retrieved 11 April 2020.

17. Zhou, M., Tang, F., Wang, Y., et al. (2020). Knowledge, attitude and practice regarding COVID19 among health care workers in Henan, China. Journal of Hospital Infection. https://doi.org/10.1016 /j.jhin.2020.04.012.

18. Zhong B-L, Luo W, Li H-M, Zhang Q-Q, Liu X-G, Li $W-T$, et al. Knowledge, attitudes, and practices towards COVID-19 among Chinese residents during the rapid rise period of the COVID-19 outbreak: a quick online cross sectional survey. Int J Biol Sci. (2020) 16:1745-52. doi: 10.7150/ijbs.45221

19. The World Health Organization Q\&A on coronaviruses (COVID-19) (2020). Retrieved April 20, 2020 from https ://www.who.int/news-room/q-adetai I/q-a-coronaviruses

20. Kassema, J. J. COVID-19 outbreak: is it a health crisis or economic crisis or both? Case of African Counties. SSRN Electr J. (2020) 9:4-14. doi: 10.2139/ssrn.3559200

21. McKibbin WJ, Fernando R. The global macroeconomic impacts of COVID- 19: seven scenarios. SSRN Electr J. (2020) 20-24. doi: 10.2139/ssrn.354772924. Clements JM. Knowledge and behaviors toward COVID-19 among US residents during the early days of the pandemic. Med Rxiv. (2020).doi: 10.1101/2020.03.31.20048967

22. Coronavirus Disease-2019: Knowledge, Attitude, and Practices of Health Care Workers at Makerere
University Teaching Hospitals, Uganda Ronald Olum1*†, Gaudencia Chekwech1, Godfrey Wekha1, Dianah Rhoda Nassozi 1 and Felix Bongomi.

23. Bhagvathula AS, Aldhaleei WA, Rahmani J, Mahabadi MA, Bandari DK (2020) Knowledge and Perceptions of COVID-19 among Health care workers: A cross-sectional study. JMIR Public Health and Surveillance 6: e19160.

24. Clements JM. Knowledge and behaviors toward COVID-19 among US residents during the early days of the pandemic. Med Rxiv. (2020). doi: 10.1101/2020.03.31.20048967

25. Zhong, B.L.; Luo, W.; Li, H.M.; Zhan, Q.Q.; Liu, X.G.; Li, W.T.; Li, Y. Knowledge, attitudes, and practices towards COVID-19 among Chinese residents during the rapid rise period of the COVID-19 outbreak: A quick online cross-sectional survey. Int. J. Biol. Sci. 2020, 16, 1745-1752. [CrossRef] [Pub Med]

26. Zhou, M., Tang, F., Wang, Y., et al. (2020). Knowledge, attitude and practice regarding COVID19 among health care workers in Henan, China. Journal of Hospital Infection. https://doi.org/10. 1016/j.jhin.2020.04.012.

27. Maleki, S., Najafi, F., Farhadi, K., et al. (2020). Knowledge, attitude and behavior of health care workers in the prevention of COVID-19. BMG Medical Education, under review. https://doi.org/ 10.21203 /rs.3.rs-23113/v1.

28. Zegarra A, Chino B, Ames R (2020) Knowlegde, Perception and Attitudes in Regard to COVID-19 Pandemic in Peruvian Population.

29. Ogolodom MP, Mbaba AN, Alazigha N, Erondu OF, Egbe NO, et al. (2020) Knowledge, Attitudes and Fears of HealthCare Workers towards the Corona Virus Disease (COVID-19) Pandemic in SouthSouth, Nigeria. Health Sci J. Sp. Iss 1: 002. DOI: 10.36648/1791-809X.S1.002.

30. Gan, W. H., Lim, J. W., \& Koh, D. (2020). Preventing intra-hospital infection and transmission of COVID19 in healthcare workers. Safety and Health at Work, $11,241$.

31. Qian, X., Ren, R., Wang, Y. et al. Fighting against the common enemy of COVID-19: a practice of building a community with a shared future for mankind. Infect Dis Poverty 9, 34 (2020). https://d oi.org/10.1186/s40249-020-00650-1

32. World Health Organization. Coronavirus Disease (COVID-19) Outbreak: Rights, roles and responsibilities of health workers, including key considerations for occupational safety and health. (2020). Retrieved May 13, 2020 from www.who.int/p ublications-detail/coronavirus-disease-(covid-19)outbreak.

33. Black JRM, Bailey C, Przewrocka J, Dijkstra KK, Swanton C. COVID-19: the case for health-care worker screening to prevent hospital transmission. Lancet. 2020; 395: 1418-1420. 
34. Marjanovic Z, Greenglass ER, Coffey S. The relevance of psychosocial variables and working conditions in predicting nurses' coping strategies during the SARS crisis: an online questionnaire survey. Int J Nurs Stud. 2007; 44: 991-998.

35. Risk of COVID-19 among front-line health-care workers and the general community: a prospective cohort study. Nguyen, Long H Albert, Christine M. et al. The Lancet Public Health, Volume 5, Issue 9, e475 - e483. DOI: https://doi.org/10.1016/S24682667(20)30164-X

36. The experiences of health-care providers during the COVID-19 crisis in China: a qualitative study. Liu, Qian et al. The Lancet Global Health, Volume 8, Issue 6, e790 - e798. 